\title{
Spinocerebellar Ataxia Type 2
}

National Cancer Institute

\section{Source}

National Cancer Institute. Spinocerebellar Ataxia Type 2. NCI Thesaurus. Code C148315.

An autosomal dominant condition caused by mutation(s) in the ATXN2 gene, encoding ataxin-2. Specifically, the mutation is an expanded CAG trinucleotide repeat in the gene. It is a progressive cerebellar ataxia associated supranuclear ophthalmoplegia, mild dementia and peripheral neuropathy. 